\title{
Adherence to Newly Implemented Tamoxifen Therapy for Breast Cancer Patients in Rural Western Ethiopia
}

\author{
Christian Felix Reibold ${ }^{\mathrm{a}}$ Wakuma Tariku $^{\mathrm{b}}$ Pia Eber-Schul ${ }^{\mathrm{a}}$ \\ Sefonias Getachew ${ }^{c}$ Adamu Addisie ${ }^{c}$ Susanne Unverzagt ${ }^{d}$ Andreas Wienke $^{d}$ \\ Steffen Hauptmann ${ }^{\mathrm{e}}$ Claudia Wickenhauser ${ }^{f}$ Martina Vetter $^{\mathrm{a}}$ \\ Ahmedin Jemal $^{g}$ Christoph Thomssen ${ }^{a}$ Eva Johanna Kantelhardt ${ }^{a}$ \\ a Department of Gynecology, Martin-Luther-University Halle-Wittenberg, Halle (Saale), Germany; \\ bEthiopian Evangelical Church of Mekane Yesus EECMY Aira Hospital, Aira, Ethiopia; 'School of Public Health, \\ Addis Ababa University, Addis Ababa, Ethiopia; ${ }^{\mathrm{d} I n s t i t u t e}$ of Medical Epidemiology, Biostatistics and Informatics, \\ Martin-Luther-University Halle-Wittenberg, Halle (Saale), Germany; ${ }^{e}$ Department of Pathology, GROW-School \\ for Oncology and Developmental Biology, Maastricht University Medical Centre, Maastricht, The Netherlands; \\ fDepartment of Pathology, Martin-Luther-University Halle-Wittenberg, Halle (Saale), Germany; \\ ${ }^{g}$ American Cancer Society, Atlanta, GA, USA
}

\section{Keywords}

Breast neoplasms · Africa · Ethiopia - Tamoxifen · Endocrine therapy

\begin{abstract}
Introduction: Endocrine therapy for breast cancer (BC) patients is highly underutilized in rural Ethiopia and other African countries. Objective: This study aims to assess the feasibility of and adherence to tamoxifen therapy in rural Ethiopia. Methods: We ascertained the hormone receptor (HR) status in 101 women diagnosed with BC from January 2010 to December 2015 and who had surgery in Aira Hospital, in rural Ethiopia. From 2013, tamoxifen was offered to patients with HR-positive $(\mathrm{HR}+)$ tumors. Prescription refill records and a structured questionnaire were used to assess receipt of and adherence to tamoxifen. Results: Of the 101 BC patients tested for HR status during the study period, 66 (65\%) patients were $\mathrm{HR}+$ and were eligible for tamoxifen treatment. However, 15 of the HR+ patients died before tamoxifen became available in 2013. Of the remaining $51 \mathrm{HR}+$ patients, $26(51 \%)$ initiated tamoxifen but only 9 of them (35\%) adhered to therapy (medication possession rate $\geq 80 \%$, me-
\end{abstract}

dian observation 16.2 months). After 1 year, 52\% of the patients were still adherent, and 9 patients had discontinued therapy. The reasons for non-initiation of tamoxifen included patient factors $(n=5)$, including financial hardship or lack of transportation, and health care provider factors $(n=12)$. Conclusions: Endocrine therapy for BC patients seems feasible in rural Western Ethiopia, although non-adherence due to financial hardship and a less developed health care infrastructure remains a major challenge. We postulate that the implementation of breast nurses could reduce patient and health system barriers and improve initiation of and adherence to endocrine treatment.

(C) 2021 The Author(s) Published by S. Karger AG, Basel

\section{Introduction}

Breast cancer $(\mathrm{BC})$ is the most common cancer and leading cause of cancer death in sub-Saharan Africa $[1,2]$, including in Ethiopia, where the estimated incidence in 2018 was $15,244[3,4]$. The estimated 2 -year survival rate in a rural hospital in Western Ethiopia was only 53\% [5] compared to 5 -year survival rates of $>81 \%$ in Europe [6].
() 2021 The Author(s)

Published by S. Karger AG, Basel

This is an Open Access article licensed under the Creative Common Attribution-NonCommercial-4.0 International License (CC BY-NC) (http://www.karger.com/Services/OpenAccessLicense), applicable to the online version of the article only. Usage and distribution for commercial purposes requires written permission.
Eva J. Kantelhardt

Department of Gynecology, Martin-Luther-University Halle-Wittenberg

Ernst-Grube-Strasse 40

DE-06097 Halle (Germany)

eva.kantelhardt@uk-halle.de 
Fig. 1. Patients eligible for analysis from those enrolled in our study over the period January 26, 2010 to December 31, 2015. Tamoxifen treatment was initiated on March 18, 2013 and the adherence assessment period was March 18, 2013 to December 31, 2015. HR, hormone receptor; TAM, tamoxifen.

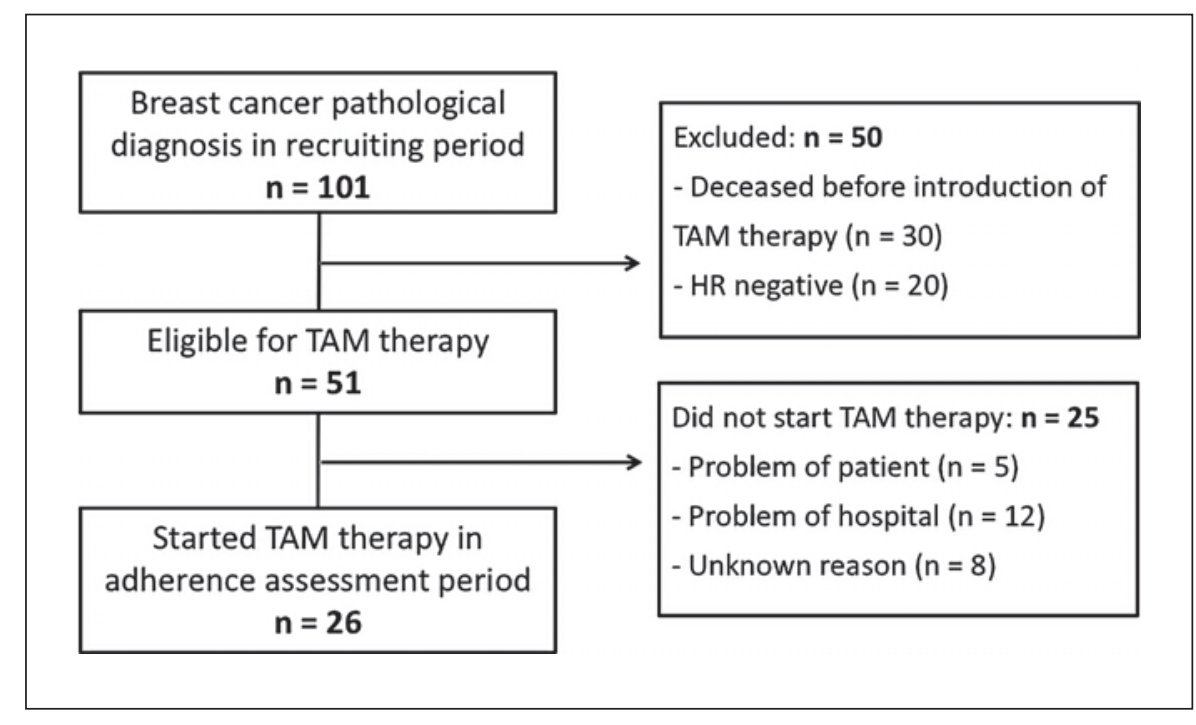

Reasons for these disparities in outcome include differences in stage at first presentation [7], availability of therapy [8], and underlying levels of investment in health care [9]. Like in many sub-Saharan African countries, only basic surgical treatment services are available at regional hospitals in Ethiopia [10]. Hospitals offering adjuvant systemic therapy and the only radiotherapy center are located in urban Addis Ababa. The majority of patients with BC face serious challenges in accessing these facilities [11] since $80 \%$ of the Ethiopian population reside in rural areas [12].

Tamoxifen is an effective treatment option for patients with hormone receptor-positive ( $\mathrm{HR}+$ ) and unknown receptor status BC $[13,14]$. It is easy to administer (oral), inexpensive, and has few serious side effects $[15,16]$. In women with $\mathrm{HR}+$ non-metastatic $\mathrm{BC}$, the absolute reduction in the risk of recurrence after 15 years with $20 \mathrm{mg}$ of tamoxifen daily over 5 years is $13.2 \%$, and the reduction in the mortality rate is $9.2 \%$ [17]. Although the majority (65\%) of BC patients in Ethiopia are HR+ [18] and tamoxifen is on the essential drug list of Ethiopia [19], it is not widely used in rural Western Ethiopia.

The Breast Cancer Initiative 2.5 developed resourcestratified guidelines for BC control in sub-Saharan Africa [20]. In line with these guidelines the National Cancer Control Plan (NCCP) of Ethiopia aims to "strengthen cancer control capacities," including de-centralization of oncology care [21].

In this pilot project, funded by the German Gynecologic Oncology Working Group (AGO), Aira Hospital in rural Western Ethiopia offered pathology workup including immunohistochemistry for the detection of HR expression and provision of tamoxifen treatment. Extreme poverty in addition to a high rate of illiteracy are thought to pose significant challenges for women to adhere to long-term tamoxifen treatment.

\section{Materials and Methods}

\section{Study Design}

This is an explorative, prospective, hospital-based cohort study to assess the feasibility of administering tamoxifen to patients with $\mathrm{BC}$ in rural Western Ethiopia. Feasibility was investigated by focusing on the adherence to therapy, defined as "the extent to which a person's behavior - taking medication [...] corresponds with agreed recommendations from a health care provider" [22].

\section{Setting}

Ethiopia has a three-tier health care system, with 1st regional Primary Health Care Units, 2nd General Regional Hospitals in zones, and 3rd Specialized Referral Hospitals. Aira Hospital in Oromia State, Western Wollega District, officially provides primary health care to 68,000 people, but unofficially serves 500,000 inhabitants due to the presence of a specialist surgeon.

The international collaboration between Aira Hospital and the Department of Gynecology, Martin Luther University (MLU) Halle-Wittenberg, Germany began in 2010. In March 2013, free endocrine treatment with tamoxifen $(20 \mathrm{mg} /$ day $)$ was provided for BC patients. Patients received tamoxifen in packages containing 30 tablets each, usually three packages (range 1-4).

\section{Participants}

All BC patients operated at Aira Hospital between January 2010 and December 2015 were included $(n=101), 66(65 \%)$ were HR+ or receptor status unknown. Of these, 15 had passed away before the initiation of treatment and 51 were eligible for tamoxifen therapy (Fig. 1). C.F.R. and a local nurse visited all $\mathrm{HR}+\mathrm{BC}$ patients in their homes in February 2016.

\section{Data Sources/Measurement}

A questionnaire obtained clinical, social, and reproductive factors. A structured interview including open questions assessed: (i) difficulties in the provision of the medication, (ii) patients' perception about the beneficial effects, and (iii) reasons for adherence or non-adherence. The questionnaire was developed by a panel of experts (W.T., C.T., E.J.K., S.U., C.F.R.) based on the MARS (Medication Adherence Rating Scale) questionnaire and considering the sociocultural context, comments from local health workers, and previous experiences [5]. 
Table 1. Patient characteristics $(n=51)$

\begin{tabular}{|c|c|}
\hline Age at diagnosis, years & 45 [35-51] \\
\hline Number of children & $4(0-11)$ \\
\hline Walking time to health center, $\mathrm{h}$ & $1.1(0.1-3)$ \\
\hline Travel time to hospital, $\mathrm{h}$ & $6.1(0.1-24)$ \\
\hline \multicolumn{2}{|l|}{ Age group } \\
\hline$<35$ years & $11(22)$ \\
\hline $35-50$ years & $25(49)$ \\
\hline$>50$ years & $15(29)$ \\
\hline Premenopausal & $24(47)$ \\
\hline Postmenopausal & $27(53)$ \\
\hline \multicolumn{2}{|l|}{ Place of residence $(n=48)$} \\
\hline Rural & $38(79)$ \\
\hline Urban & $10(21)$ \\
\hline \multicolumn{2}{|l|}{ Religion $(n=48)$} \\
\hline Christian & $38(79)$ \\
\hline Muslim & $9(19)$ \\
\hline Other & $1(2)$ \\
\hline \multicolumn{2}{|l|}{ Literate $(n=38)$} \\
\hline No & $31(77)$ \\
\hline Yes & $9(23)$ \\
\hline \multicolumn{2}{|l|}{ Profession $(n=49)$} \\
\hline Housewife & $28(57)$ \\
\hline Farmer & $17(35)$ \\
\hline Student & $1(2)$ \\
\hline Other & $3(6)$ \\
\hline \multicolumn{2}{|l|}{ Marital status $(n=41)$} \\
\hline Married & $38(93)$ \\
\hline Not married & $3(7)$ \\
\hline \multicolumn{2}{|l|}{ Survival status } \\
\hline Deceased & $21(46)$ \\
\hline Alive & $21(35)$ \\
\hline Unknown & $9(18)$ \\
\hline \multicolumn{2}{|l|}{ AJCC stage $(n=33)$} \\
\hline 1 & $2(6)$ \\
\hline 2 & $10(30)$ \\
\hline 3 & $20(61)$ \\
\hline 4 & $1(3)$ \\
\hline \multicolumn{2}{|l|}{ Clinical tumor size $(n=38)$} \\
\hline $\mathrm{T} 1$ & $3(6)$ \\
\hline T2 & $22(46)$ \\
\hline T3 & $18(38)$ \\
\hline $\mathrm{T} 4$ & $5(10)$ \\
\hline \multicolumn{2}{|l|}{ Pathological diagnosis } \\
\hline NST & $47(92)$ \\
\hline Other & $4(8)$ \\
\hline \multicolumn{2}{|l|}{ Grading } \\
\hline Grade 1 & $3(6)$ \\
\hline Grade 2 & $14(27)$ \\
\hline Grade 3 & $34(67)$ \\
\hline \multicolumn{2}{|l|}{ HR status } \\
\hline $\mathrm{ER}+\mathrm{PgR}+$ & $28(55)$ \\
\hline $\mathrm{ER}+\mathrm{PgR}-$ & $9(18)$ \\
\hline ER-PgR+ & $12(23)$ \\
\hline Unknown & $2(4)$ \\
\hline \multicolumn{2}{|l|}{ HER2 } \\
\hline Negative ( 0 to $2+$ ) & $39(76)$ \\
\hline Positive (3+) & $10(20)$ \\
\hline \multirow{2}{*}{\multicolumn{2}{|c|}{ Ki-67 }} \\
\hline & \\
\hline Negative $(<14 \%)$ & $16(31)$ \\
\hline Positive & $33(65)$ \\
\hline Unknown & $2(4)$ \\
\hline Surgical treatment $(n=44)$ & \\
\hline Modified radical mastectomy & $15(34)$ \\
\hline Simple mastectomy & $4(9)$ \\
\hline Radical mastectomy & $1(2)$ \\
\hline Lumpectomy $^{1}$ & $7(16)$ \\
\hline Quadrantectomy $^{1}$ & $6(14)$ \\
\hline Mastectomy (not specified) & $11(25)$ \\
\hline
\end{tabular}

Data are presented as the mean [IQR], mean (range), or $n(\%)$. AJCC, American Joint Committee on Cancer; ER, estrogen receptor; PgR, progesterone receptor; NST, non-specific type of BC.

${ }^{1}$ No irradiation in breast-conserving therapy.
The questionnaire was translated from English into local Oromifa then proofread and revised. A local nurse with experience in qualitative research read the questions to the patients and they answered in their local language. Patient perception was only assessed for a total of 22 patients alive. Computer-based prescription refill records were also used to assess implementation, initiation, and treatment persistence (adherence). Clinical and pathological information was obtained from the patient files.

\section{Definitions}

Adherence is defined by initiation, implementation, and discontinuation [23]. Initiation is the date of the first handover of tamoxifen. Implementation equates to the medication possession ratio (MPR), which describes the patient's medication intake compared to the prescribed drug dosing regimen [24]. An MPR of $\geq 80 \%$ was defined as an acceptable adherence [25]. Discontinuation occurred when the patient stopped taking tamoxifen and did not present for a refill. In this study, discontinuation was defined as a refill gap of more than 6 months [26]. Adherence was defined as the length of time between initiation and last dose before discontinuation. Descriptive statistical analyses were performed using SPSS version 22.0 (IBM, Armonk, NY, USA).

\section{Results}

Of the study population of 101 patients, due to predefined criteria, a total of 51 patients were eligible for tamoxifen therapy. Table 1 shows characteristics of eligible women. The mean age at diagnosis was 45 years (IQR 35-51). Almost 80\% were residents outside Aira. Most women were illiterate $(77 \%)$. The mean walking time to the next health center (nurse available) was about $1.1 \mathrm{~h}$ (range $0.1-3$ ) and travel to Aira hospital (physicians available) required $6.1 \mathrm{~h}$ (range $0.1-24$ ). At the time of diagnosis, the vast majority of the patients had stage 2 or 3 disease $(n=30 / 33 ; 91 \%)$. One third $(n=15 / 44 ; 34 \%)$ underwent modified radical mastectomy; due to lack of consent, lumpectomy $(n=7 ; 16 \%)$ and quadrantectomy ( $n=6 ; 14 \%)$ were also performed. Of 51 patients eligible for tamoxifen therapy, 25 (49\%) did not initiate endocrine treatment. The reasons for non-initiation included problems on the health care provider side $(12 ; 48 \%)$ where patients had not been given an appointment $(n=9)$, the physician was absent $(n=2)$, and other $(n=1)$. Reasons on the patient side $(13 ; 52 \%)$ included lack of money $(n=$ $2)$, too weak to travel $(n=1)$, fear of treatment $(n=1)$, and private reasons $(n=1)$. No information was available for 8 patients. One patient explained: "I went to the hospital, and the surgeon was not at the hospital, or maybe didn't know about my presence."

During the observed March 2013 to December 2015 treatment adherence assessment period, of the 26 patients who initiated tamoxifen therapy (Fig. 1), 9 discontinued treatment (Table 2). One patient recounted, "I took two tablets a day and then waited for the appointment," although she had already finished her medication. Another 
Table 2. Patient perception of tamoxifen

\begin{tabular}{|c|c|}
\hline $\begin{array}{l}\text { Symptom duration, months } \\
\text { Time to treatment of those patients } \\
\text { operated in the adherence assessment period, months }\end{array}$ & $5.7(0.1-10.8)$ \\
\hline \multicolumn{2}{|l|}{ Questionnaire } \\
\hline \multicolumn{2}{|c|}{$\begin{array}{l}\text { What is the most important medical problem for women in this area? } \\
(n=22)\end{array}$} \\
\hline "No idea" & $14(64)$ \\
\hline Back pain & $3(14)$ \\
\hline Cervical cancer & $3(14)$ \\
\hline Mastitis & $1(4)$ \\
\hline Gastritis & $1(4)$ \\
\hline \multicolumn{2}{|l|}{ What is cancer? $(n=22)$} \\
\hline "No idea" & $11(50)$ \\
\hline Disease & $5(23)$ \\
\hline Deadly disease & $6(27)$ \\
\hline \multicolumn{2}{|l|}{ Do you have cancer? $(n=20)$} \\
\hline No & $10(50)$ \\
\hline Yes & $10(50)$ \\
\hline \multicolumn{2}{|l|}{ Is tamoxifen necessary? $(n=19)$} \\
\hline No & $0(0)$ \\
\hline Yes & $19(100)$ \\
\hline \multicolumn{2}{|l|}{ Would you pay for tamoxifen? $(n=14)$} \\
\hline No & $11(79)$ \\
\hline Yes & $3(21)$ \\
\hline \multicolumn{2}{|l|}{ Wherefore do you take tamoxifen? $(n=17)$} \\
\hline "No idea" & $6(35)$ \\
\hline Prevents cancer & $9(53)$ \\
\hline Is helpful & $1(6)$ \\
\hline Minders the power of cancer & $1(6)$ \\
\hline \multicolumn{2}{|l|}{ Why did you stop taking tamoxifen? $(n=9)$} \\
\hline Terminal illness & $2(22)$ \\
\hline Difficult circumstances & $2(22)$ \\
\hline Lack of money & $2(22)$ \\
\hline Side effects of therapy & $2(22)$ \\
\hline Unknown & $1(11)$ \\
\hline \multicolumn{2}{|c|}{$\begin{array}{l}\text { Describe complaints on your health }(n=20 \text {; more than one answer } \\
\text { possible) }\end{array}$} \\
\hline None & $14(41)$ \\
\hline Nausea & $3(9)$ \\
\hline Hot flushes & $3(9)$ \\
\hline Sweating & $6(18)$ \\
\hline Vaginal discharge & $1(3)$ \\
\hline Diarrhea & $1(3)$ \\
\hline Changes in mood & $2(5)$ \\
\hline Other & $4(12)$ \\
\hline \multicolumn{2}{|c|}{$\begin{array}{l}\text { Describe discomforts with the taking of tamoxifen }(n=21 \text {; more than } \\
\text { one answer possible) }\end{array}$} \\
\hline "No problems" & $14(59)$ \\
\hline Difficult to swallow & $7(29)$ \\
\hline Interrupts daily work & $2(8)$ \\
\hline Reminds of the disease & $1(4)$ \\
\hline
\end{tabular}

Data are presented as the mean (IQR) or number of answering patients (\%). $n=22$ of 26 who initiated tamoxifen; families of 3 deceased patients were not found, and 1 husband was unable to answer the questionnaire

woman said, "I missed one appointment because my child was sick and I was afraid of presenting too late." One woman described tamoxifen as "hard medicine" causing epigastric burning and vomiting. Another shared she "had to borrow money from neighbors for traveling."

Figure 2 provides the patients' refill and possession data for tamoxifen with a resolution of 10 days for the 26 patients who initiated tamoxifen treatment. All except 2 patients had at least one refill delay of 10 days. Of the women who received surgery and initiated adjuvant tamoxifen, most $(7 ; 58 \%)$ of the 12 patients experienced a long delay from the time of operation to the initiation of tamoxifen (median 5.7 months; IQR 0.1-10.8).

The mean MPR was 54\% (IQR 28-89). During a median observation time of 16.2 months (range 1-35.7), 17 patients (65.4\%) took less than $80 \%$ of the prescribed dose and were declared non-adherent, while 9 patients (34.6\%) were adherent to therapy. After 1 year the Kaplan-Meier estimated proportion of persistence to therapy was 52\%; 6 patients took tamoxifen for more than 1 year (Fig. 3).

Table 2 shows the results of open questions on the patient self-reported perception of health and treatment. The mean time between the first breast symptoms and the patient's presentation at the hospital was 22.4 months (IQR 6-24). Half of the patients had "no idea" what cancer is. At least a few identified cancer as a disease or as a "killer disease." Tamoxifen was considered necessary to all patients, but only 3 were willing to pay for it. Two thirds identified tamoxifen as an anti-cancer drug. For some patients, tamoxifen was difficult to swallow, interrupted daily work, or reminded them of the disease.

\section{Discussion}

About half the patients in rural Ethiopia initiated the therapy and of those, half still used the medication after 1 year. Limited data are available concerning the adherence to tamoxifen therapy in Africa. A study from Nigeria reported very high adherence rates of $75.5 \%$ after 1 year in an urban setting [27]. Data from Europe and the USA show that 90 and $74.6 \%$ of $\mathrm{BC}$ patients take up adjuvant endocrine therapy $[28,29]$. Generally, reviews on endocrine treatment reveal a great range of adherence of between 41 and $93.4 \%$ after 1 year (including non-initiation and discontinuation) [30,31].

\section{Challenges on the Health Care Provider Side}

According to the incidence rates of $\mathrm{BC}$ in Ethiopia, and a population coverage of 500,000, $488 \mathrm{BC}$ patients were expected at Aira Hospital within 5 years compared to the actual cohort of 101 patients, revealing significant underutilization of the service. The non-initiation and delay of initiation of tamoxifen treatment in this study reflects common shortcomings in rural settings in sub-Saharan Africa of inadequate pathology capacity and infrastructure $[32,33]$ and a small number of overburdened physicians [34]. Additional staff including dedicated cancer nurses to track and navigate patients may enhance initiation and adherence and avoid ineffective discontinuation of chronic tamoxifen treatment. A step forward would be the implementation of local pathology and better referral services to increase initiation and adherence. 


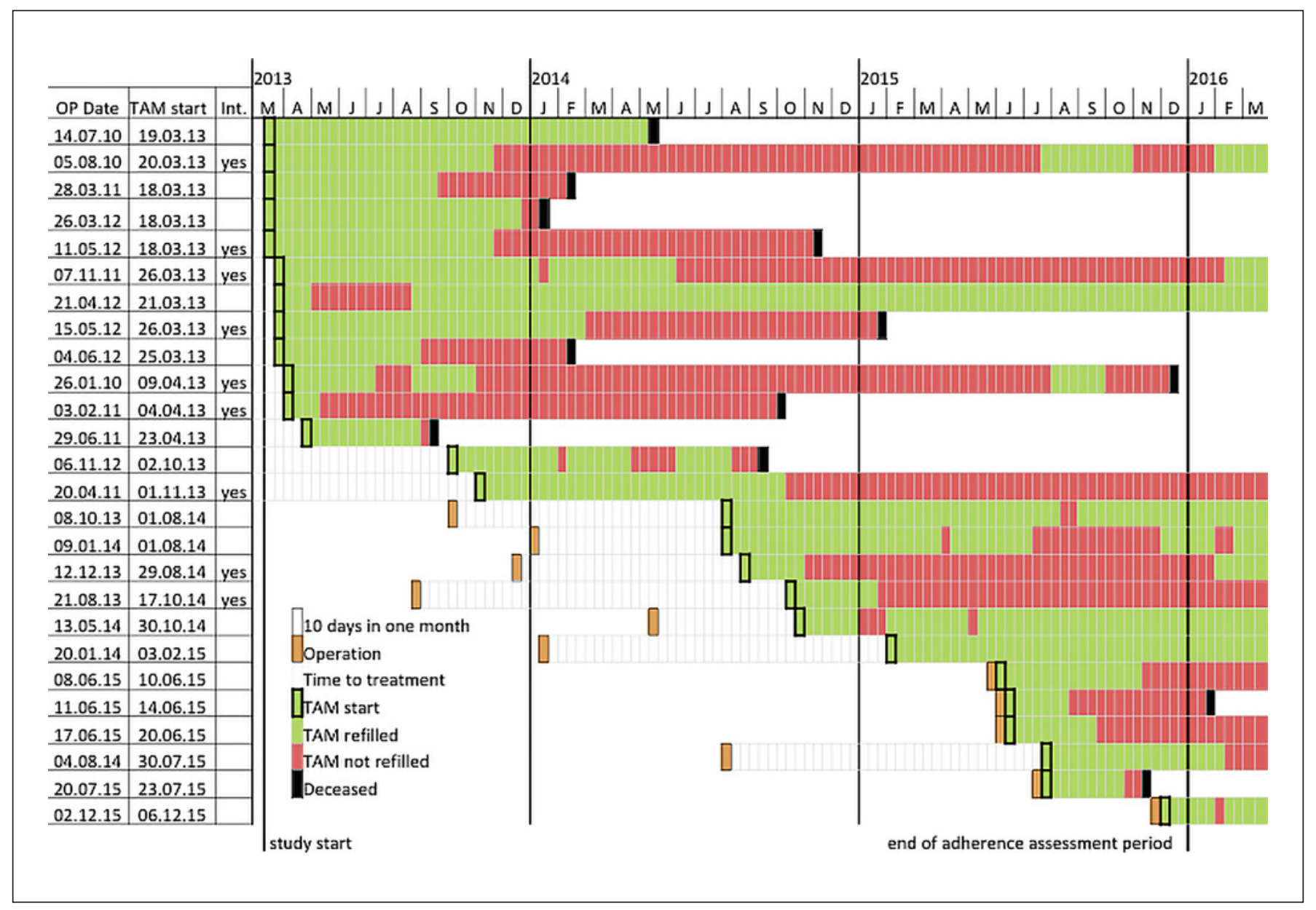

Fig. 2. Summary of 3-year adherence assessments for the 26 patients who initiated tamoxifen treatment and were censored for prescription refill between March 26, 2013 and March 10, 2016. TAM, tamoxifen; Int., interrupted; OP, operation.

Fig. 3. Kaplan-Meier estimates of the duration of tamoxifen therapy. Discontinuation: no patient contact for more than 6 months, 9 events in 26 patients.

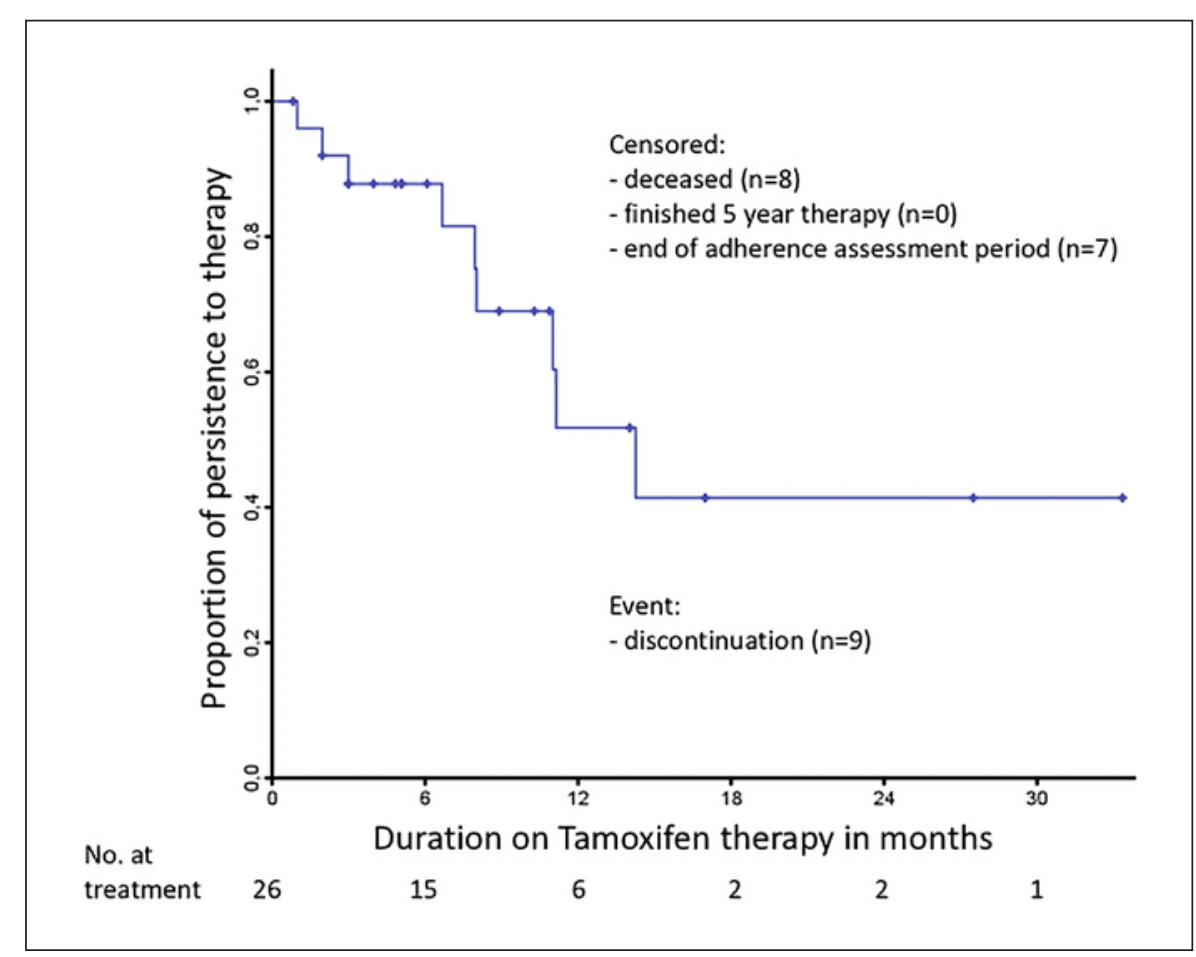




\section{Challenges on the Patient Side}

A review showed that high out-of-pocket costs are associated with poor adherence to chronic cancer treatment [30] and remain a barrier to adequate health care access [35]. A Nigerian study listed costs for the drugs, laboratory expenses, and transportation to the hospital as the most common reasons for non-adherence [36]. Although this study minimized financial efforts, they were still the main reason for discontinuation or non-initiation on the patient side. Tamoxifen has been available in Addis Ababa since 1999 in private pharmacies [37]. As most people in rural parts of Ethiopia are farmers with a low income, the average cost of living of about USD 70/month makes tamoxifen (USD 9/month) inaccessible in remote areas (personal inquiry).

Being convinced of the necessity of medication seems to be an important factor in adherence [38]. Patients who understand their disease are more likely to adhere to therapy $[25,39]$. Although most patients in this study were convinced of the necessity of tamoxifen, half of the patients in this study had "no idea" what cancer is and they stopped therapy at some time. Reminders and encouragement by SMS or phone calls has improved adherence to HIV medication in South Africa [40]. Patient education and pharmacotherapeutic follow up by health professionals such as breast nurses could be helpful in improving adherence to endocrine treatment [31]. A study in Ghana suggested that women are more likely to complete treatment (71.4\%) if they know a person who survived cancer [41]. Therefore, long-term survivors should be included in awareness campaigns to demonstrate the effect of continuous treatment.

\section{Limitations}

First, the sample size of our study is small. There could be selection bias since wealthy patients would be more able to access the hospital and very poor patients were probably among the estimated $80 \%$ who never arrived at the hospital. Second, the adherence (continuation after initiation) of those patients who initiated therapy and who already understood the necessity of treatment was assessed. These patients could have a better adherence than those who did not initiate any therapy. It follows that even if the adherence rate in this study was low, findings may still overestimate the adherence rate of all patients. Third, a potential bias of the qualitative data could be the suggestive character of the questionnaire and imprecise answers about adherence by relatives of deceased patients. Such an influence was minimized by performing the structured interviews in the local language with a nurse experienced in qualitative research and home visits. We have shown that most BCs in Ethiopia are HR+ [5, 42]; therefore, implementation of endocrine treatment is a promising approach in Ethiopia. The administration of endocrine ther- apy in rural Ethiopia was implemented, but major challenges remained. Histopathological reports including diagnosis and immunohistochemical services were fully supplied from outside the system; tamoxifen was given by donation. Patient education and navigation was identified as a major shortcoming. Comprehensive interventions to improve system-wide issues in health institutions and to improve patient engagement are needed. One potential health care provider intervention is training and allocating time for breast nurses. We agree with the Lancet series on health, equity, and women's cancers in suggesting a persuasive opportunity for breast nurses to educate patients, administer tamoxifen, and relieve the burden of cancer patients [43]. In alignment with the NCCP, we state that treatment for cancer patients must be subsidized by government in low-income rural settings [21].

\section{Statement of Ethics}

This study was approved by the institutional review boards at Addis Ababa University, Ethiopia (study approval's reference No. 050/2013 protocol 124/10/IM), and MLU Halle-Wittenberg, Germany (vote on August 23, 2010 of the "Medizinische Ethikkommission"). Informed consent was obtained from all patients when the pathology specimens were sent to Germany for analysis. Additional consent was obtained when tamoxifen therapy was started.

\section{Conflict of Interest Statement}

The authors declare no conflicts of interest related to this paper.

\section{Funding Sources}

This research was supported by the Else Kröner-Fresenius-Stiftung grant 2014_HA72, through a private donation project by the Department of Gynecology, Martin Luther University, Halle (Saale), Germany, and by members of the German Gynecologic Oncology Working Group (AGO), Breast Committee.

\section{Author Contributions}

C.F.R., W.T., E.J.K., and C.T. designed the study. C.F.R., P.E.S., and W.T. acquired the data. S.G. and A.A. organized the project. C.F.R., S.U., and A.W. performed the statistical analysis. S.H., C.W., and M.V. performed the pathological services. E.J.K. and C.W. obtained the funding. C.F.R. and E.J.K. drafted the manuscript. A.J. critically read and revised the manuscript. All authors substantially contributed to the interpretation of data for the work, critically revised the manuscript, approved the final version, and agreed to be accountable for all aspects of the work. 


\section{References}

1 Siegel R, Naishadham D, Jemal A. Cancer statistics, 2012. CA Cancer J Clin. 2012;62(1):10 29.

2 International Agency for Research on Cancer. GLOBOCAN 2012: estimated cancer incidence, mortality and prevalence worldwide in 2012. Lyon: IARC; 2012.

3 International Agency for Research on Cancer. GLOBOCAN 2018: estimated cancer incidence, mortality and prevalence worldwide in 2018. Lyon: IARC; 2018.

4 Timotewos G, Solomon A, Mathewos A, Addissie A, Bogale S, Wondemagegnehu $\mathrm{T}$, et al. First data from a population based cancer registry in Ethiopia. Cancer Epidemiol. 2018 Apr; 53:93-8.

5 Eber-Schulz P, Tariku W, Reibold C, Addissie A, Wickenhauser C, Fathke C, et al. Survival of breast cancer patients in rural Ethiopia. Breast Cancer Res Treat. 2018 Jul;170(1):111-8.

6 Allemani C, Sant M, Weir HK, Richardson LC, Baili $\mathrm{P}$, Storm $\mathrm{H}$, et al. Breast cancer survival in the US and Europe: a CONCORD high-resolution study. Int J Cancer. 2013 Mar;132(5): 1170-81.

7 Jedy-Agba E, McCormack V, Adebamowo C, Dos-Santos-Silva I. Stage at diagnosis of breast cancer in sub-Saharan Africa: a systematic review and meta-analysis. Lancet Glob Health. 2016 Dec;4(12):e923-35.

8 Allemani C, Weir HK, Carreira H, Harewood R, Spika D, Wang XS, et al. Global surveillance of cancer survival 1995-2009: analysis of individual data for $25,676,887$ patients from 279 population-based registries in 67 countries (CONCORD-2). Lancet. 2015;385(9972):9771010 .

9 Ginsburg O, Bray F, Coleman MP, Vanderpuye V, Eniu A, Kotha SR, et al. The global burden of women's cancers: a grand challenge in global health. Lancet. 2017;389:847-60.

10 Kingham TP, Alatise OI, Vanderpuye V, Casper C, Abantanga FA, Kamara TB, et al. Treatment of cancer in sub-Saharan Africa. Lancet Oncol. 2013 Apr;14(4):e158-67.

11 Dye TD, Bogale S, Hobden C, Tilahun Y, Hechter V, Deressa T, et al. Complex care systems in developing countries: breast cancer patient navigation in Ethiopia. Cancer. $2010 \mathrm{Feb}$; 116(3):577-85.

12 World Health Organisation. Ethiopia [cited 2018 Jun 6]. Available from: http://www.who. int/countries/eth/en/

13 National Comprehensive Cancer Network. NCCN clinical practice guidelines in oncology: breast cancer. Plymouth Meeting: NCCN; 2016.

14 AGO. Adjuvant endocrine therapy in pre- and postmenopausal patients; 2015. Taufkirchen: AGO; 2015.

15 Echavarria MI, Anderson BO, Duggan C, Thompson B. Global uptake of BHGI guidelines for breast cancer. Lancet Oncol. 2014 Dec;15(13):1421-3.

16 Gradishar WJ, Anderson BO. Balassanian Ron. Breast cancer, version 4.2017, NCCN clinical practice guidelines in oncology. J Natl Compr Canc Netw. 2018;16(3);310-20.

17 Davies C, Godwin J, Gray R, Clarke M, Cutter D, Darby S, et al.; Early Breast Cancer Trialists'
Collaborative Group (EBCTCG). Relevance of breast cancer hormone receptors and other factors to the efficacy of adjuvant tamoxifen: patient-level meta-analysis of randomised trials. Lancet. 2011 Aug;378(9793):771-84.

18 Kantelhardt EJ, Mathewos A, Aynalem A, Wondemagegnehu T, Jemal A, Vetter M, et al. The prevalence of estrogen receptor-negative breast cancer in Ethiopia. BMC Cancer. 2014 Nov; 14(1):895.

19 Food, Medicine and Healthcare Administration and Control Authority of Ethiopia. National Essential Medicine List, 5th ed. Addis Ababa; 2014.

20 Duggan C, Dvaladze AL, Tsu V, Jeronimo J, Constant TK, Romanoff A, et al. Resourcestratified implementation of a communitybased breast cancer management programme in Peru. Lancet Oncol. 2017 Oct;18(10):e60717.

21 Federal Ministry of Health Ethiopia. National Cancer Control Plan 2016 - 2020 [cited 2020 May 13]. Available from: URL: https://www. iccp-portal.org/system/files/plans/NCCP\%20 Ethiopia\%20Final\%20.pdf.

22 Organization World Health. Adherence to long-term therapies: Evidence for action. Geneva: WHO; 2003

23 Vrijens B, De Geest S, Hughes DA, Przemyslaw K, Demonceau J, Ruppar T, et al.; ABC Project Team. A new taxonomy for describing and defining adherence to medications. Br J Clin Pharmacol. 2012 May;73(5):691-705.

24 Vrijens B, Vincze G, Kristanto P, Urquhart J, Burnier M. Adherence to prescribed antihypertensive drug treatments: longitudinal study of electronically compiled dosing histories. BMJ. 2008 May;336(7653):1114-7.

25 Simon R, Latreille J, Matte C, Desjardins P, Bergeron E. Adherence to adjuvant endocrine therapy in estrogen receptor-positive breast cancer patients with regular follow-up. Can J Surg. 2014 Feb;57(1):26-32.

26 Boyles TH, Wilkinson LS, Leisegang R, Maartens G. Factors influencing retention in care after starting antiretroviral therapy in a rural South African programme. PLoS One. 2011 May;6(5):e19201.

27 Oguntola AS, Adeoti ML, Akanbi O. Non-adherence to the use of tamoxifen in the first year by the breast cancer patients in an African population. Association of Surgeons of East Africa and College of Surgeons of East Central and Southern Africa; 2011. http://hdl.handle. net/1807/52865.

28 Farias AJ, Du XL. Racial Differences in Adjuvant Endocrine Therapy Use and Discontinuation in Association with Mortality among Medicare Breast Cancer Patients by Receptor Status. Cancer Epidemiol Biomarkers Prev. 2017 Aug;26(8):1266-75.

29 Van Ewijk RJ, Schwentner L, Wöckel A, König J, Kreienberg R, Blettner M; BRENDA study group. Trends in patient characteristics, treatment and survival in breast cancer in a nonselected retrospective clinical cohort study of 2,600 patients. Arch Gynecol Obstet. 2013 Jan; 287(1):103-10.

30 Murphy CC, Bartholomew LK, Carpentier MY, Bluethmann SM, Vernon SW. Adherence to adjuvant hormonal therapy among breast cancer survivors in clinical practice: a systematic review. Breast Cancer Res Treat. 2012 Jul; 134(2):459-78.

31 Ayres LR, Baldoni AO, Borges AP, Pereira LR. Baldoni, André de Oliveira, Borges, Anna Paula de Sá, Pereira, Leonardo Régis Leira. Adherence and discontinuation of oral hormonal therapy in patients with hormone receptor positive breast cancer. Int J Clin Pharm. 2014; 36(1):45-54.

32 Adesina A, Chumba D, Nelson AM, Orem J, Roberts DJ, Wabinga $\mathrm{H}$, et al. Improvement of pathology in sub-Saharan Africa. Lancet Oncol. 2013 Apr;14(4):e152-7.

33 Gelband H, Sankaranarayanan R, Gauvreau CL, Horton S, Anderson BO, Bray F, et al. Costs, affordability, and feasibility of an essential package of cancer control interventions in low-income and middle-income countries: key messages from Disease Control Priorities, 3rd edition. Lancet. 2016;387:2133-44.

34 Tankwanchi AB, Ozden C, Vermund SH. Physician emigration from sub-Saharan Africa to the United States: analysis of the 2011 AMA Physician Masterfile. PLoS Med. 2013; 10(9):e1001513.

35 Denny L, de Sanjose S, Mutebi M, Anderson BO, Kim J, Jeronimo J, et al. Interventions to close the divide for women with breast and cervical cancer between low-income and middleincome countries and high-income countries. Lancet. 2017;389:861-70.

36 Anyanwu SN, Egwuonwu OA, Ihekwoaba EC. Acceptance and adherence to treatment among breast cancer patients in Eastern Nigeria. Breast. 2011 Apr;20 Suppl 2:S51-3.

37 Reeler AV, Sikora K, Solomon B. Overcoming challenges of cancer treatment programmes in developing countries: a sustainable breast cancer initiative in Ethiopia. Clin Oncol. 2008 Mar;20(2):191-8.

38 Grunfeld EA, Hunter MS, Sikka P, Mittal S. Adherence beliefs among breast cancer patients taking tamoxifen. Patient Educ Couns. 2005 Oct;59(1):97-102.

39 Chlebowski RT, Kim J, Haque R. Adherence to endocrine therapy in breast cancer adjuvant and prevention settings. Cancer Prev Res. 2014 Apr;7(4):378-87.

40 Georgette N, Siedner MJ, Zanoni B, Sibaya T, Petty CR, Carpenter S et al. The acceptability and perceived usefulness of a weekly clinical SMS program to promote HIV antiretroviral medication adherence in KwaZulu-Natal, South Africa. AIDS Behav. 2016;20:2629-38.

41 Obrist M, Osei-Bonsu E, Awuah B, WatanabeGalloway S, Merajver SD, Schmid K et al. Factors related to incomplete treatment of breast cancer in Kumasi, Ghana. Breast. 2014;23: 821-8.

42 Kantelhardt EJ, Zerche P, Mathewos A, Trocchi $\mathrm{P}$, Addissie A, Aynalem A, et al. Breast cancer survival in Ethiopia: a cohort study of 1,070 women. Int J Cancer. 2014 Aug;135(3):702-9.

43 Ginsburg O, Badwe R, Boyle P, Derricks G, Dare A, Evans T, et al. Changing global policy to deliver safe, equitable, and affordable care for women's cancers. Lancet. 2017;389:87180 . 